\title{
Pharmacokinetics and Tissue Residues of Tylosin in Broiler Chickens
}

\author{
Ahmed M. Soliman ${ }^{*}$, Mahmoud Sedeik ${ }^{2}$ \\ ${ }^{1}$ Department of Pharmacology, Faculty of Veterinary Medicine, Cairo University, Giza, Egypt \\ ${ }^{2}$ Department of Poultry and Fish Diseases, Faculty of Veterinary Medicine, Alexandria University, Alexandria, \\ Egypt \\ Email: "galalpharma@hotmail.com, galalpharma@cu.edu.eg
}

Received 29 October 2015; accepted 15 January 2016; published 18 January 2016

Copyright (C) 2016 by authors and Scientific Research Publishing Inc.

This work is licensed under the Creative Commons Attribution International License (CC BY).

http://creativecommons.org/licenses/by/4.0/

(c) (i) Open Access

\section{Abstract}

The pharmacokinetics and tissue residue of tylosin in broiler chickens were studied after I.V. and oral administrations in a dose of $50 \mathrm{mg}$ tylosin/kg.b.wt. Tylosin was obeyed a two-compartment open model following I.V. administration at a dose of $50 \mathrm{mg} / \mathrm{kg} . \mathrm{b} . \mathrm{wt}$. The disposition kinetics of tylosin following I.V. administration revealed that tylosin was highly distributed with $\mathrm{V}_{\mathrm{d}(\text { area) }}$ of 6 $\mathrm{L} / \mathrm{kg}$ and eliminated with half-life $\left(\mathrm{t}_{1 / 2 \beta}\right)$ equal to 7.29 hours. The disposition kinetics of tylosin following oral administration revealed that the maximum blood concentration $\left(C_{\max }\right)$ was 3.40 $\mu \mathrm{g} / \mathrm{ml}$ attained at $\left(t_{\max }\right)$ of 1.08 hour. Tylosin was eliminated with half-life $\left(t_{1 / 2 \beta}\right)$ equal to 5.78 hours. The mean systemic bioavailability of tylosin after oral administration was $90.29 \%$. Following repeated oral administration of $50 \mathrm{mg}$ tylosin base/kg.b.wt once daily for 5 consecutive days, the blood $(\mu \mathrm{g} / \mathrm{ml})$ and tissue $(\mu \mathrm{g} / \mathrm{g})$ residues of tylosin showed that liver, kidney and lung contained the highest tylosin residues and completely disappeared from those tissues at 6 days after the last oral dose. Chickens should not be slaughtered for human consumption within the treatment and 6 days after the last oral administrations of tylosin.

\section{Keywords}

Pharmacokinetics, Tylosin, Broiler Chickens, Bioavailability, Tissue Residue

\section{Introduction}

Antibiotics, normally administrated via food or drinking water, are used by veterinarians for therapy, prophylaxis and growth promotion in broilers and laying hens. As a result there is concern that residues of this drug may be retained in meat or eggs from treated hens. It is therefore essential to obtain data for the target tissues for

*Corresponding author. 
this drug in chickens [1] [2]. The macrolide antibiotics are a group of structurally similar compounds, most of which are derived from various species of Streptomyces soil-borne bacteria [3]. Tylosin is a macrolide antibiotic registered exclusively for veterinary use and was first described by [4]. Tylosin is active against Gram-positive bacteria, anaerobic bacteria and mycoplasmas [5]. It is indicated primarily for the treatment of chronic respiratory disease complex caused by Mycoplasma gallisepticum and synoviae in chickens and infectious sinusitis in turkeys [2] [6] [7]. Tylosin, erythromycin and tilmicosin have found the most clinical applications of the macrolide class in veterinary medicine. New derivatives such as azithromycin are increasing in popularity. Other macrolides such as oleandomycin and carbomycin have been used as feed additives for growth promotion in food animals [7]. The antibacterial action of tylosin is due to inhibition of protein synthesis by binding to the 50S, ribosomal subunit of organisms [8] [9]. Although most authors have listed macrolides as bacteriostatic at therapeutic concentrations [10], they can be slowly bactericidal action with time dependent effects [11].

Despite the extensive use of tylosin in poultry industry, limited information is currently available about pharmacokinetic disposition of tylosin in broiler [2]. Accordingly, the main purpose of this study is to investigate and provide an overview of the pharmacokinetics, blood and tissue residues of tylosin in Tylan Soluble ${ }^{\circledR}$ to determine the withdrawal time in healthy broiler chickens.

\section{Materials and Methods}

\subsection{Drugs}

Tylan Soluble ${ }^{\circledR}$ (Elanco, UK) is a water soluble powder dispensed as tylosin tartrate $100 \mathrm{~g}$.

\subsection{Experimental Design}

Ten single comb white leghorn healthy broiler chickens (2 months of age) weighing 2000 - 2250 gm were chosen from Tanta Poultry Farm, Egypt. They were kept individually in cages, within a ventilated, heated room $\left(20^{\circ} \mathrm{C}\right)$ and 14 hours of day light. They received a standard commercial ration free from any antibiotics for 30 days before starting the experiment (to withdraw any antibiotic residues) and water ad libitum. All procedures involving animals were reviewed and approved by the Institutional Animal Care and Use Committee (IACUC) of Cairo University.

\subsection{Pharmacokinetics Study}

Ten chickens were used to study the pharmacokinetics of tylosin following intravenous and oral administrations. Chickens were injected intravenously in the left wing vein with $50 \mathrm{mg}$ tylosin base/kg.b.wt (from tylosin tartarate, Sigma Aldrich ${ }^{\circledR}$ according to the product instruction). Chicken were left for 15 days to ensure complete excretion of the tylosin from their bodies and were administered orally (intracrop) with Tylan Soluble ${ }^{\circledR}$ in a dose of $50 \mathrm{mg}$ tylosin base/kg.b.wt.

\subsection{Tissue Residues Study}

Fifteen clinically normal Hubbard chickens of 2 - 3 months, weighing 1800 - 2200 g were chosen randomly from Tanta Poultry Farm, Egypt. Chicken were fed on a balanced ration free from antibiotic for 2 weeks to withdraw any antibiotic residues.

Tissue residue of tylosin in Tylan Soluble ${ }^{\circledR}$ was determined following repeated oral administrations of $50 \mathrm{mg}$ tylosin base/kg.b.wt once daily for 5 consecutive days. After the end of the fifth day of repeated oral administration, three chickens were slaughtered at 24, 48, 72, 96 and 120 hours for both drugs, respectively.

\subsection{Blood and Tissue Samples}

One ml of blood was collected from right wing vein after a single intravenous or oral administrations at intervals of 5, 15, 30 minutes, 1, 2, 4, 6, 8, 12 and 24 hours. Blood samples were collected in dry centrifuge tubes. Serum was separated by centrifugation (2000 r.p.m/10 minutes) and stored at $-20^{\circ} \mathrm{C}$ until tylosin assay.

After the end of the fifth day of repeated oral administrations of Tylan Soluble ${ }^{\circledR}$, three chickens were slaughtered at 24, 48, 72, 96 and 120 hours, from each slaughtered chicken, blood, lung, liver, kidney and muscles were taken for drug assay. Samples were frozen and stored at $-20^{\circ} \mathrm{C}$ until tylosin assay. 


\subsection{Analytical Procedure}

The analytical procedure was described by Arret et al., 1971 [12] and modified by Tsai and Konda, 2001 [13], a cylinder plate diffusion assay technique which used with a single layer of agar medium II (Difco). About $1 \mathrm{ml}$ of the spore suspension of Bordetella bronchiseptica (ATCC 4617) obtained from the Department of Microbiology, Faculty of Veterinary Medicine, Cairo University, Egypt. The organism was added to $100 \mathrm{ml}$ agar II (at $55^{\circ} \mathrm{C}$ $60^{\circ} \mathrm{C}$ ). The mixture was shacked thoroughly till complete mixing of the test organism with the agar. Petri dishes $(120 \times 20 \mathrm{~mm})$ with flat ad even bottoms were placed on a levels glass plate, and about $25 \mathrm{ml}$ of inoculated medium was added to each dish by using a sterile cylinder ( $25 \mathrm{ml}$ capacity) to form a thin layer of uniform thickness. After complete solidification six wells were made on the surface of inoculated agar using stainless steel cylinder with sharp edges ( $10 \pm 0.1 \mathrm{~mm}$ length, $8 \pm 0.1 \mathrm{~mm}$ outside diameter, and $6 \pm 0.1 \mathrm{~mm}$ inside diameter $)$ careful vertical punching creates ells that were clean and symmetric. A paper grid system under the plate facilitates the even spacing of the wells that allows for triplicate determination of standards and samples.

Three plates were used for each sample; three wells on each plate were filled with the reference concentration ( $5 \mu \mathrm{g}$ of tylosin per milliliter free serum or phosphate buffer). The other three wells were filled with the sample (serum or tissues). The plates were incubated at $37^{\circ} \mathrm{C}$ for $16-18$ hours. The diameter of each inhibition zone was measured. The average diameter of the inhibition zone of the samples was corrected by using the zone diameter of the reference concentration, the concentration corresponding to the corrected values of the zone diameter was obtained.

\subsection{Pharmacokinetic and Statistical Analysis}

The pharmacokinetic parameters of tylosin were calculated by using a non-compartmental software program (WinNonlin ${ }^{\circledR}$ software, version 5.2, Pharsight Corporation, NC, USA). The area under the serum concentrationtime curve (AUC) was calculated using the trapezoidal rule with extrapolation to infinity. The maximum concentration $\left(\mathrm{C}_{\max }\right)$ and the corresponding peak time $\left(\mathrm{t}_{\max }\right)$ were determined by the inspection of the individual drug serum concentration-time profiles. The slope of the terminal phase of the time-concentration curve was determined by linear regression and converted to an elimination half-life $\left(\mathrm{t}_{1 / 2 \beta}\right)$ by multiplying the reciprocal by 0.693 .

\subsection{Bioavailability}

The rate of absorption after oral administration was determined by comparing the area under the serum concentration-time curve (AUC) oral with that obtained following intravenous injection (AUC) i.v. in the same chicken.

$$
\text { Bioavailability }=\frac{(\mathrm{AUC})_{\text {oral }} \times \mathrm{D}_{\mathrm{i} . \mathrm{v}}}{(\mathrm{AUC})_{\text {i.v }} \times \mathrm{D}_{\text {oral }}} \times 100
$$

where: $\mathrm{D}_{\mathrm{iv}}=$ Dose of intravenous injection;

$\mathrm{D}_{\text {oral }}=$ Dose of oral administration.

Data were expressed as $\mathrm{X} \pm \mathrm{SE}$ and were statistically analyzed using analysis of variance. Mean comparisons were performed using Tukey's test. The differences were considered significant when $p<0.05$. These calculations were performed using Prism 5.0 (GraphPad).

\section{Results}

The mean serum concentration-time curve of tylosin in Tylan Soluble ${ }^{\circledR}$ following I.V. and oral administration is plotted and presented graphically in Figure 1. The pharmacokinetic parameters of tylosin in Tylan Soluble ${ }^{\circledR}$ following I.V. and oral administration of tylosin $50 \mathrm{mg} / \mathrm{kg}$.b.wt in broiler chickens were calculated and showed in Table 1, Table 2. The disposition kinetics of tylosin following I.V. administration revealed that tylosin was highly distributed with $\mathrm{V}_{\mathrm{d}(\text { area }}$ of $6 \mathrm{~L} / \mathrm{kg}$ and eliminated with half-life $\left(\mathrm{t}_{1 / 2 \beta}\right)$ equal to 7.29 hours. The disposition kinetics of tylosin in Tylan Soluble ${ }^{\circledR}$ following oral administration of $50 \mathrm{mg} / \mathrm{kg} . b . w t$ tylosin base $/ \mathrm{kg} . b . w t$ revealed that the maximum blood concentration [ $\left.\mathrm{C}_{\max }\right]$ was $3.40 \mu \mathrm{g} / \mathrm{ml}$ and attained at $\left[\mathrm{t}_{\max }\right]$ of 1.08 hours. Tylosin in Tylan Soluble ${ }^{\circledR}$ was eliminated with half-life $\left[\mathrm{t}_{1 / 2 \beta}\right]$ equal to 5.78 hours. The mean systemic bioav-ailability of tylosin following oral administration in broiler chickens was $90.29 \%$. The oral bioavailability of Tylan Soluble ${ }^{\circledR}$ 


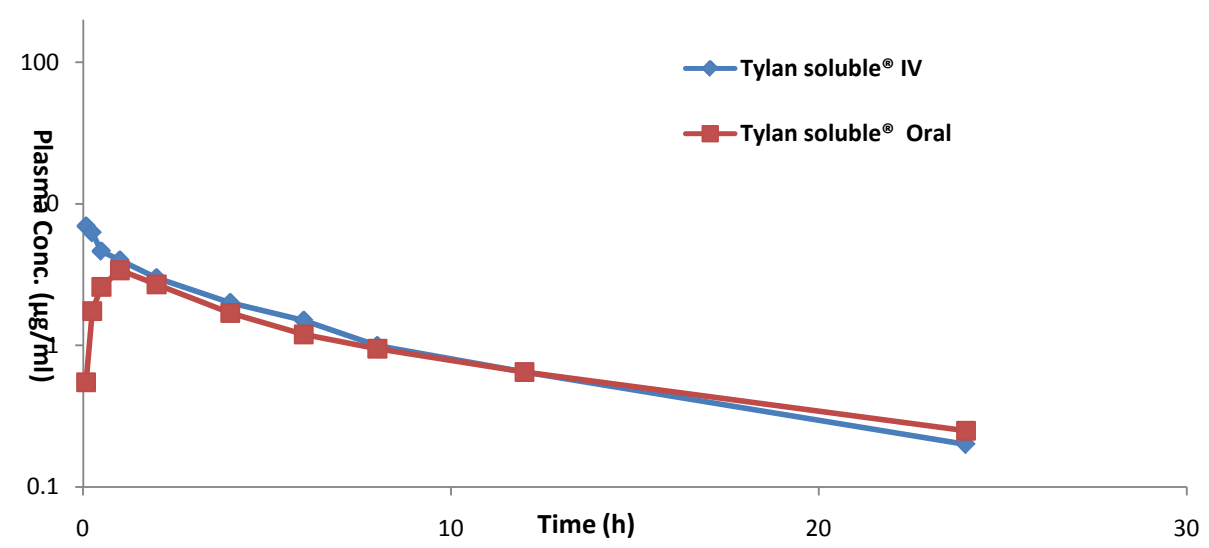

Figure 1. Semilogarthimic plot showing the serum concentrations-time profile of tylosin in Tylan Soluble ${ }^{\circledR}$ following intravenous and oral administration in broiler chickens $(\mathrm{n}=10)$.

Table 1. Pharmacokinetic parameters of tylosin in Tylan Soluble ${ }^{\circledR}$ following I.V. administration of $50 \mathrm{mg}$ tylosin base/kg.b.wt in broiler chickens $(\mathrm{n}=10)$, mean \pm S.E.

\begin{tabular}{ccc}
\hline Parameters & Unit & Tylan Soluble $^{\circledR}$ \\
$\mathbf{C}^{\mathbf{0}}$ & $\mu \mathrm{g} / \mathrm{ml}$ & $4.50 \pm 0.25$ \\
$\mathbf{t}_{1 / 2 \alpha}$ & $\mathrm{h}$ & $0.385 \pm 0.08$ \\
$\mathbf{V}_{\mathbf{c}}$ & $\mathrm{L} / \mathrm{kg}$ & $2.60 \pm 0.15$ \\
$\mathbf{V}_{\mathbf{d}(\text { area }}$ & $\mathrm{L} / \mathrm{kg}$ & $6.00 \pm 0.65$ \\
$\mathbf{V}_{\text {dss }}$ & $\mathrm{L} / \mathrm{kg}$ & $5.30 \pm 0.40$ \\
$\mathbf{K}_{\mathbf{1 2}}$ & $\mathrm{h}^{-1}$ & $0.77 \pm 0.05$ \\
$\mathbf{K}_{21}$ & $\mathrm{~h}^{-1}$ & $0.82 \pm 0.05$ \\
$\mathbf{t}_{1 / 2 \beta}$ & $\mathrm{h}$ & $7.29 \pm 0.75$ \\
$\mathbf{C l}_{\mathbf{B}}$ & $\mathrm{L} / \mathrm{kg} / \mathrm{h}$ & $0.005 \pm 0.008$ \\
$\mathbf{A U C}_{0-\infty}$ & $\mu \mathrm{g} \cdot \mathrm{h} / \mathrm{ml}$ & $20.60 \pm 2.05$
\end{tabular}

$\mathrm{C}^{0}=$ Drug concentration in serum at zero time immediatly after a single intravenous injection; $\mathrm{AUC}_{0-\infty}=$ area under the concentration-time curve from zero up to $\infty$ with extrapolation of the terminal phase; $\mathrm{t}_{1 / 2 \beta}=$ half-life of the elimination; $\mathrm{V}_{\mathrm{c}}$ $=$ volume of the central compartment; $\mathrm{Vd}_{\mathrm{area}}=$ Volume calculated by the area method; $\mathrm{V}_{\mathrm{dss}}=$ apparent volume of distribution at steady-state; $\mathrm{Cl}_{\mathrm{B}}=$ clearance from the body. $\mathrm{K}_{12}=$ First order transfer rate constant for drug distribution from central to peripheral compartment ; $\mathrm{K}_{21}=$ First order transfer rate constant for drug distribution from peripheral to central compartment.

Table 2. Pharmacokinetic parameters of tylosin in Tylan Soluble ${ }^{\circledR}$ following oral administration of $50 \mathrm{mg}$ tylosin base/kg.b.wt in broiler chickens $(\mathrm{n}=10)$, Mean \pm S.E.

\begin{tabular}{ccc}
\hline Parameters & Unit & Tylan Soluble $^{\circledR}$ \\
$\mathbf{k}_{\mathbf{a b}}$ & $\mathrm{h}^{-1}$ & $3.60 \pm 0.65$ \\
$\mathbf{t}_{\mathbf{1} / \mathbf{a b}}$ & $\mathrm{h}$ & $0.19 \pm 0.08$ \\
$\mathbf{t}_{1 / 2 \beta}$ & $\mathrm{h}$ & $5.78 \pm 0.50$ \\
$\mathbf{t}_{\max .}$ & $\mathrm{h}$ & $1.08 \pm 0.20$ \\
$\mathbf{C}_{\text {max. }}$ & $\mu \mathrm{g} / \mathrm{ml}$ & $3.40 \pm 0.25$ \\
$\mathbf{C l}_{\mathbf{B}}$ & $\mathrm{L} / \mathrm{kg} / \mathrm{h}$ & $0.002 \pm 0.005$ \\
$\mathbf{A U C}$ & $\mu \mathrm{g} \cdot \mathrm{h} / \mathrm{ml}$ & $18.60 \pm 1.50$ \\
Bioavailability & $\%$ & $90.29 \pm 2.10$
\end{tabular}

$\mathrm{C}_{\max }=$ maximal concentration; $\mathrm{t}_{\max }=$ when the maximal serum concentration is reached; $\mathrm{AUC}_{0-\mathrm{t}}=$ area under serum concentration-time curve; $\mathrm{t}_{1 / 2 \beta}=$ Elimination half-life; $\mathrm{K}_{\mathrm{ab}}=$ first-order absorption rate constant; $\mathrm{t}_{1 / 2 \mathrm{ab}}=$ The $\mathrm{absorption}$ half-life (h). 
Table 3. Blood levels $(\mu \mathrm{g} / \mathrm{ml})$ and tissue concentrations $(\mu \mathrm{g} / \mathrm{g})$ of tylosin in Tylan Soluble ${ }^{\circledR}$ following repeated oral administrations of $50 \mathrm{mg}$ tylosin base/kg.b.wt once daily for five consecutive days in broiler chickens $(\mathrm{n}=3)$, Mean \pm S.E.

\begin{tabular}{cccccccc}
\hline \multirow{2}{*}{ Blood and tissues } & \multicolumn{5}{c}{ Time after the last dose (hours) } \\
\cline { 2 - 7 } & $\mathbf{2 4}$ & $\mathbf{4 8}$ & $\mathbf{7 2}$ & $\mathbf{9 6}$ & $\mathbf{1 2 0}$ & $\mathbf{1 4 4}$ \\
\hline Blood & $3.85 \pm 0.16$ & $1.40 \pm 0.09$ & $0.35 \pm 0.01$ & N.D & N.D & N.D \\
Lung & $39.0 \pm 3.37$ & $21.0 \pm 1.78$ & $8.35 \pm 0.75$ & $1.0 \pm 0.05$ & N.D & N.D \\
Liver & $42.0 \pm 4.11$ & $26.0 \pm 3.18$ & $13.0 \pm 1.11$ & $4.0 \pm 0.50$ & $1.0 \pm 0.04$ & N.D \\
Kidney & $55.0 \pm 5.93$ & $33.0 \pm 4.48$ & $16.0 \pm 2.59$ & $7.0 \pm 0.46$ & $2.0 \pm 0.06$ & N.D \\
Muscles & $15.0 \pm 1.13$ & $6.0 \pm 1.25$ & $2.0 \pm 0.45$ & $0.50 \pm 0.03$ & N.D & N.D \\
\hline
\end{tabular}

N.D $=$ Not detected. After the end of the fifth day of repeated oral administrations, three chickens were slaughtered at $24,48,72,96,120$ and 144 hours.

indicated a good absorption from GIT which indicated that this formulation is advised to be given orally in case of acute systemic bacterial infections.

Blood and tissue residues of tylosin in Tylan Soluble ${ }^{\circledR}$ in slaughtered chickens following repeated oral administrations of $50 \mathrm{mg} / \mathrm{kg}$.b.wt tylosin base/kg.b.wt once daily for 5 consecutive days are recorded in Table 3 . The represented data revealed a good spread distribution of tylosin in Tylan Soluble ${ }^{\circledR}$ in lung, liver, kidney and muscles.

\section{Discussion}

Antibiotics are widely used as veterinary drugs or as feed additives to promote growth. Some studies had induced pharmacokinetic data in poultry [14]-[19]. Tylosin was obeyed a two compartments open model following I.V. administration at a dose of $50 \mathrm{mg} / \mathrm{kg} . b . w t$. This result is consistent with [20]. Tylosin in Tylan Soluble ${ }^{\circledR}$ was highly distributed with great extent to all tissues $V_{c}, V_{d}$ area and $V_{d s s}$; (exceeded one liter $/ \mathrm{kg}$ ). This correlated with the rapid transfer of tylosin from central compartment to the peripheral one $\left(\mathrm{k}_{12}\right)$ than its passage from peripheral to the central compartment $\left(\mathrm{k}_{21}\right)$ [21] [22]; a factor revealed that tylosin is the drug of choice for attacking the systemic infections caused by sensitive organisms.

Tylosin in Tylan Soluble ${ }^{\circledR}$ following IV administration obeyed a two compartments-open model. This indicated that tylosin distributed in the body of chicken in two compartments; a central one which represent blood and highly perfused organs (kidney-liver-spleen-heart) and a $2^{\text {nd }}$ peripheral compartment which represented by skin and connective tissues [2] [23].

The disposition kinetics of tylosin in Tylan Soluble ${ }^{\circledR}$ following oral administration of $50 \mathrm{mg}$ tylosin $/ \mathrm{kg}$.b.wt revealed that the maximum blood concentration $\left[\mathrm{C}_{\max }\right.$. $]$ were $3.40 \mu \mathrm{g} / \mathrm{ml}$ and attained at $\left[\mathrm{t}_{\max }\right]$ of 1.08 hours and was eliminated with half-lives $\left(\mathrm{t}_{1 / 2 \beta}\right)$ equal to 5.78 hours. These results are consistent with those recorded in cows [24] and some avian species [25]-[27]. The higher volume of distribution of tylosin was also recorded in chickens [2] [22].

The mean systemic bioavailability of tylosin in Tylan Soluble ${ }^{\circledR}$ following oral administration was $90.29 \%$. [2] and [28] stated that tylosin had good absorption from the GIT and no enteric coating is required to maintain the stability of the compound in the stomach. It is widely distributed to basically the same tissues as described for tylosin, metabolized by the liver and excreted via the bile and feces.

Blood and tissue residues of tylosin in Tylan Soluble ${ }^{\circledR}$ in slaughtered chickens following repeated oral administrations of $50 \mathrm{mg}$ tylosin/kg.b.wt once daily for 5 consecutive days revealed a wide spread distribution of tylosin in Tylan Soluble ${ }^{\circledR}$ in lung, liver, kidney, muscles. Liver, kidney and lung contained the highest drug residues, while the lowest concentration showed in blood. Tylan Soluble ${ }^{\circledR}$ was completely cleared from blood and all tissues at 5 days (120 hours) after the last dose. These data were consistent with those reported by [17].

[29] concluded and recommended that microbiological ADI of $6 \mu \mathrm{g} / \mathrm{kg} . b . w t ~(360 \mu g$ per $60 \mathrm{~kg}$ person) was established for tylosin.

Tylosin residues in Tylan Soluble ${ }^{\circledR}$ was the MRLs approved by [30]. These results are consistent with those investigated in broiler chickens [2] [22] [26]. 


\section{Conclusion}

The oral bioavailability of tylosin in Tylan Soluble ${ }^{\circledR}$ indicated a good absorption from GIT. This indicated that Tylan Soluble ${ }^{\circledR}$ is advised to be given orally in case of acute bacterial attacks in blood and other organs. In addition, chickens should not be slaughtered for human consumption within the treatment and 6 days after the last oral administration of tylosin in Tylan Soluble ${ }^{\circledR}$.

\section{Acknowledgements}

The authors would like to express their sincere gratitude to Dr. Ahmed Samir (Department of Microbiology, Faculty of Veterinary Medicine, Cairo University) for his great effort in preparation of microbial suspension and helping in the bio-assay technique in this project.

\section{Conflict of Interests}

The author declares that there is no conflict of interests regarding the publication of this paper.

\section{References}

[1] Furusawa, N. (1999) Spiramycin, Oxytetracycline and Sulphamono-Methoxine Contents of Eggs and Egg-Forming Tissues of Laying Hens. Journal of Veterinary Medicine Series A, 46, 599-603. http://dx.doi.org/10.1046/j.1439-0442.1999.00247.x

[2] Kowalski, C., Rolinski, Z., Zan, R. and Wawron, W. (2002) Pharmacokinetics of Tylosin in Broiler Chickens. Polish Journal of Veterinary Science, 5, 127-130.

[3] Scott, P.R., McGowan, M., Sargison, N.D., Penny, C.D. and Lowman, B.G. (1996) Use of Tilmicosin in a Severe Outbreak of Respiratory Disease in Weaned Beef Calves. Australian Veterinary Journal, 73, 62-64. http://dx.doi.org/10.1111/j.1751-0813.1996.tb09967.x

[4] Stark, W.M., Daily, W.A. and McGuire, J.M. (1961) A Fermentation Study of the Biosynthesis of Tylosin in Synthetic Media. Scientific Report of the Istituto Superiore di Sanita, 1, 340-354.

[5] Giguere, S. (2006) Lincosamindes, Macrolides, and Pleuromutilins. In: Antimicrobial Therapy in Veterinary Medicine, 4th Edition, Wiley Blackwell, Ames, 179-190.

[6] Montesissa, C., DeLiguoro, M., Santi, A., Capolongo, F. and Biancotto, G. (1999) Tylosin Depletion in Edible Tissues of Turkeys. Food Additives and Contaminants, 16, 405-410. http://dx.doi.org/10.1080/026520399283795

[7] Kong, K., Yuan, Z., Fan, S., Wang, D., Qin, I.T., Zhou, S., Yang, E. and Cai, J. (1999) HPLC Analysis of Erythromycin Residues in Broiler Tissues. Chinese Journal of Veterinary Science, 19, 489-491.

[8] Musser, J., Mechor, G.D., Grohn, Y.T., Dubovi, E.J. and Shin, S. (1996) Comparison of Tilmicosin with Long-Acting Oxytetracyline for Treatment of Respiratory Tract Disease in Calves. Journal of the American Veterinary Medical Association, 208, 102-106.

[9] Gaynor, M. and Mankin, A.S. (2005) Macrolide Antibiotics: Binding Site, Mechanism of Action, Resistance. Frontiers in Medicinal Chemistry, 2, 21-35. http://dx.doi.org/10.2174/1567204052931113

[10] Wilson, R.C. (1984) Macrolides in Veterinary Medicine. In: Omura, S., Ed., Macrolide Antibiotics. Chemistry, Biology, and Practice, Academic Press, Inc., 301-347.

[11] Carbon, C. (1998) Pharmcodynamics of Macrolides, Azalides, and Streptogramins: Effect on Extracellular Pathogens. Clinical Infectious Disease, 27, 28-32. http://cid.oxfordjournals.org/content/27/1/28.full.pdf http://dx.doi.org/10.1086/514619

[12] Arret, B., Johnson, D.P. and Kirshbaum, A. (1971) Outline of Details for Microbiological Assay of Antibiotics. 2nd Revision. Journal of Pharmaceutical Sciences, 60, 1689-1694. http://dx.doi.org/10.1002/jps.2600601122

[13] Tsai, G.E. and Kondo, F. (2001) Improved Agar Diffusion Method for Detecting Residual Antimicrobial Agents. Journal of Food Protection, 64, 361-366.

[14] Yoshida, M., Kubota, D., Yonezawa, S., Nakamura, H., Azechi, H. and Terakado, N. (1971) Transfer of Dietary Spiramycin into the Eggs and Its Residue in the Liver of Laying Hen. Japan Poultry Science, 8, 103-110. https://www.jstage.jst.go.jp/article/jpsa1964/8/2/8_2_103/_pdf http://dx.doi.org/10.2141/jpsa.8.103

[15] Yoshida, M., Kubota, D., Yonezawa, S., Nakamura, H., Yamaoka, R. and Yoshimura, H. (1973) Transfer of Dietary Erythromycin into the Eggs and Its Residue in the Liver of Laying Hen. Japan Poultry Science, 10, 29-36. http://dx.doi.org/10.2141/jpsa.10.29 
[16] Roudaut, B., Moretain, J.P. and Biosseau, J. (1987) Excretion of Oxytetracycline in Egg after Medication of Laying Hens. Food Additives and Contaminants, 4, 297-307. http://dx.doi.org/10.2141/jpsa.10.29

[17] Roudaut, B. and Moretain, J.P. (1990) Residues of Macrolide Antibiotics in Eggs Following Medication of Laying Hens. British Poultry Science, 31, 661-675. http://dx.doi.org/10.1080/00071669008417297

[18] Yashimura, M., Osawa, D., Rasa, F.C.S., Hermawati, D., Werdiningsihi, S., Isriyanthi, N.M.R. and Sugimoto, T. (1991) Residues of Doxycycline and Oxytetracycline in Eggs after Medication via Drinking Water to Laying Hens. Food Additives and Contaminants, 8, 65-69. http://dx.doi.org/10.1080/02652039109373956

[19] Omija, B., Mittema, E.S. and Maitho, T.E. (1994) Oxytetracycline Residue Levels in Chicken Eggs after Oral Administration of Medicated Drinking Water to Laying Hens. Food Additives and Contaminants, 11, 641-647. http://dx.doi.org/10.1080/02652039409374265

[20] Ji, L.-W., Dong, L.-L., Ji, H., Feng, X.-W., Li, D., Ding, R.-L. and Jiang, S.-X. (2014) Comparative Pharmacokinetics and Bioavailability of Tylosin Tartrate and Tylosin Phosphate after a Single Oral and i.v. Administration in Chickens. Journal of Veterinary Pharmacology and Therapeutics, 37, 312-315. http://dx.doi.org/10.1111/jvp.12092

[21] Burrows, G.E., Barto, P.B., Martin, B. and Tripp, M.L. (1983) Comparative Pharmacokinetics of Antibiotics in Newborn Calves: Chloramphenical, Lincomycin and Tylosin. American Journal of Veterinary Research, 44, 1053-1057.

[22] Atef, M., El-Gendi, A.Y.I., Amer, A.M. and Kamel, G.M. (2009) Pharmacokinetic Assessment of Tylosin Concomitantly Administered with Two Anticoccidials; Diclazuril and Halofuginone in Broiler Chickens. Advances in Environmental Biology, 3, 210-218. http://www.insipub.com/aensi/aeb/2009/210-218.pdf

[23] Atef, M., Youssef, S.A., Atta, A.H. and El-Maaz, A.A. (1991) Disposition of Tylosin in Goats. British Veterinary Journal, 147, 207-215. http://dx.doi.org/10.1016/0007-1935(91)90045-O

[24] Gingerich, D., Baggot, J. and Kowalski, J. (1977) Erythromycin Antimicrobial Activity and Pharmacokinetics in Cows. Canadian Veterinary Journal, 18, 96-100.

[25] Locke, D., Bush, M. and Carpenter, J.W. (1982) Pharmacokinetics and Tissue Concentrations of Tylosin in Selected Avian Species. American Journal of Veterinary Research, 43, 1807-1810.

[26] Cezary, K. and Malgorzata, P. (2006) Evaluation of Bioequivalence of Two Tylosin Formulations after Oral Administration in Broiler Chickens. ANNALES, 3, 25-29.

[27] Abu-Basha, E.A., Al-Shunnaq, A.F. and Gehring, R. (2012) Comparative Pharmacokinetics and Bioavailability of Two Tylosin Formulations in Chickens after Oral Administration. Journal of the Hellenic Veterinary Medical Society, 63, 159-165.

[28] Ziv, G. and Sulman, F.G. (1973) Passage of Polymyxins from Serum into Milk in Ewes. American Journal of Veterinary Research, 34, 317-322.

[29] European Agency for the Evaluation of European Medicines Agency (EMEA) (2002) Committee for Veterinary Medicinal Products (Tylosin) Extension to Eggs; Summary Report (4). The European Agency for the Evaluation of Medicinal Products; London.

[30] European Agency for the Evaluation of European Medicines Agency (EMEA) (2000) Committee for Veterinary Medicinal Products (Tylosin) Extension to Eggs; Summary Report (4). The European Agency for the Evaluation of Medicinal Products; London.

http://www.ema.europa.eu/docs/en_GB/document_library/Maximum_Residue_Limits_-_Report/2009/11/WC5000157 $\underline{67 . p d f}$ 